\title{
Fish Bone in Bectum: Inlet Unharmed?
}

Robin George, Anjali Alex, Krishnan Prasad

From the Department of GI Surgery, Sree Narayana

Institute of Medical Sciences, Kochi, Kerala, India.

\section{Abstract:}

Fish bones in rectum are a rare finding not commonly published in medical literature. It may seem too simple to overlook, but, the damage they can cause internally can be quite catastrophic ranging from abrasions to fecal peritonitis. This is a report of such an unusual case of a rectal foreign body.

Key words: Rectum, Peritonitis, Foreign Bodies, Digital Rectal Examination.

\section{Introduction}

Rectal foreign bodies in the form of bones, plastic materials are an unusually common finding in clinical practice. Reports of foreign body within the rectum are uncommon in Asia, and the majority of case series are reported from Eastern Europe [1]. A fishbone that was accidentally ingested could navigate through the entire gastrointestinal tract being harmless or harmful. Numerous case reports have been reported in literature where the bone has caused perforations in internal organs. Very rarily, it has been found that a fishbone has navigated without perforating the inlet or outlet. Hence, we present a case of a 40 year patient who came to us with fish bone entrapment in the rectum without any harm to inlet.

\section{Case Report}

A 40 year old gentleman, presented in the surgical clinic with severe pain and bleeding per rectum since morning. The symptoms occurred while he attempted to pass stools, resulting in excruciating pain and bleeding. The patient felt something poking his anal canal while squatting. Attempts to remove it, failed, resulting in profuse bleeding. He recalls having rice \& fish curry for lunch the previous day at a family function. There was no history of throat pain or abdominal pain during the last 24 hours. He gave a medical history of hypertension \& non insulin dependent diabetes mellitus since 5 years. On examination, his vitals were found to be stable. Per rectal examination revealed a foreign body felt $6 \mathrm{cms}$ from anal verge with blood on the examining finger. There was also a fissure palpable, which probably resulted from straining at stools. An X-ray taken in the squatting position revealed no significant findings. Lord's dilation was done under spinal anesthesia immediately. Gentle proctoscopy revealed a remnant of the fishbone protruding through the mucosa at the

\section{Corresponding Author: Dr. Robin George}

Email: docrg7@hotmail.com

Received: May 14, 2013 | Accepted: May 27, 2013 | Published Online: June 25, 2013

This is an Open Access article distributed under the terms of the Creative Commons Attribution License (creativecommons.org/licenses/by/3.0)

Conflict of interest: None declared | Source of funding: Nil | DOI: http://dx.doi.org/10.17659/01.2013.0046 
anorectal junction [Fig.1]. Removing it using an artery forceps, revealed a small opening of 6 mm diameter at the site of insertion. The mucosal perforation was closed with $3 / 0$ chromic catgut. A rectal pack was placed to ensure perfect hemostasis. The patient was admitted in observation for few days to rule out any signs of impending peritonitis. The patient was discharged after 7 days with no residual problems.

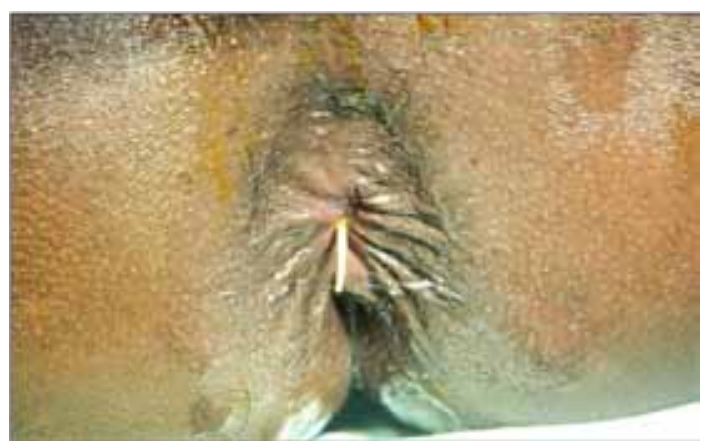

Fig.1: Fish bone in rectum

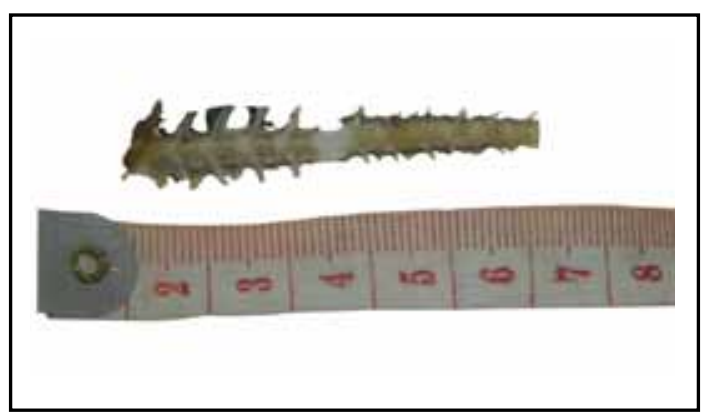

Fig.2: Fish bone gross specimen

\section{Discussion}

Accidental fish bone ingestion is quite a common occurrence, not always regarded as a highly threatening event. As fish is a regular part of South Indian meal, ingestion of bone turns out to be an inevitable risk, associated in daily eating habits.

A retrospective study of 1,338 patients conducted in a Chinese hospital by Lai et al, revealed that fish bone (62.7 per cent) was the commonest type of foreign body ingested [2]. Most of the ingested foreign bodies pass through gastrointestinal tract uneventfully within a week [3]. But, owing to the sharp nature of bone; may cause perforation of hollow visceral organs. It may pass successfully, but can lodge at the anorectal junction. Foreign bodies at times get lodged in the mid rectum, where they are unable to negotiate the anterior angulations of the rectum. Most can be felt on digital rectal examination. With appropriate sedation, most of the rectal foreign bodies can be extracted transanally: either in the emergency department or operative suite under direct vision [4]. If the foreign body is palpable and can be visualized; subcutaneous and submucosal injections 
of $0.5 \%$ lidocaine can be given, the anus can be dilated with a rectal retractor and the foreign body grasped and removed. Removing a rectal foreign body may be risky and should be done by a surgeon or surgical gastroenterologist trained in foreign body removal. Batho and Szanto stressed the importance of the removing of the foreign bodies as soon as possible in any acute abdomen [5]. Abdominal examination and chest $X$-rays may be necessary to exclude possible intraperitoneal rectal perforation. Sigmoidoscopy is required following extraction to evaluate mucosal injury or perforation [4]. Operative intervention is needed in minority of the patients who develop signs of peritonitis [6]. Possible interventions could include a proctoscopy, sigmoidoscopic retrieval of rectal foreign bodies, or laparotomy with subsequent stoma, closure of perforation or Hartman's procedure.

This particular patient was unaware of the presence of a bone in his gastrointestinal tract, so it was just ignored. His sensing the presence of a foreign body prompted him to self extract, causing pain and bleeding. In such cases, every practitioner must have high suspicion of the potential injuries and complications lying underneath that may have been incurred by a sharp foreign object. A detailed clinical history and physical examination are essential for the diagnosis and management of any such lesions [7]. The patient could be asymptomatic or may present with peritonitis. Acute peritonitis is frequently caused by perforation. As the bacterial infection spreads to affect the peritoneum in general, the condition becomes serious and septic shock can develop. Proper investigations and appropriate management is a must. With the unfortunate presence of diabetes mellitus, any rectal injury should not be taken lightly. Perforation by a fish bone is definitely not an ordinary tale to churn out.

\section{Conclusion}

Though the patient's condition was stable with the exception of diabetes mellitus, rectal foreign bodies which includes fish bones should always be considered potentially harmful. Due to the potential complications thereof, the injuries incurred should be regarded serious and treated expeditiously.

\section{References}

1. Akhtar MA, Arora PK. Case of unusual foreign body in the rectum. Saudi J Gastroenterol. 2009;15:131 132.

2. Lai AT, Chow TL, Lee DT, Kwok SP. Risk factors predicting the development of complications after foreign body ingestion. Br J Surg. 2003;90:1531-1535.

3. McCanse DE, Kurchin A, Hinshaw JR. Gastrointestinal foreign bodies. Am J Surg. 1981;1 42:335-337.

4. Cohen JS, Sackier JM. Management of colorectal foreign bodies. J R Coll Surg Edinb. 1996;41:312315.

5. Batho G, Szanto L. Foreign bodies in the rectum at our department during the last ten years. Magy Seb. 2000;53:180-182.

6. Huang, WC, Jiang, JK, Wang HS, Yang SH, Chen WS, Lin TC, et al. Retained rectal foreign bodies. J Chin Med Assoc. 2003; 66:607-612.

7. Ruiz del Castillo J, Selles Dechent R, Millan Scheiding M, Zumarraga Navas, Ascencio Arana F. Colorectal trauma caused by foreign bodies introduced during sexual activity: diagnosis and management. Rev Esp Enferm Dig. $2001 ; 93: 631-634$. 
8. Paulev PE. Gastrointestinal function and disorders. In: Paulev PE. Textbook in medical physiology and pathophysiology. Copenhagen: Copenhagen Medical Publishers; 2000. pp.24.

9. G.M. El Sherbiny. Fish Bone Ingested a Month Ago, Unharmed the Inlet but Injured the Outlet. The Internet Journal of Emergency and Intensive Care Medicine. 2007; Volume 10 Number 2. DOI: 10.5580/25bd 